\title{
Study on Dynamic Analysis Technology of Oil Reservoir during Super High Water Cut Period
}

\author{
Jiying Liu \\ No.1 oil Filed Geological Team, No.3 Oil Production plant, Daqing Oilfield Co., Ltd., Daqing \\ 163000, China.
}

\begin{abstract}
The dynamic analysis of oil reservoir development is an important means to help people understand oil reservoir, at the same time manage and rebuild oil reservoir, and scientifically and effectively develop oil reservoir. The most important link for dynamic analysis is the unit dynamic analysis. The technology of unit dynamic analysis is mainly studied in this paper, the actual water content and the recovery degree of the unit are integrated, and the water content increase rate and water storage rate are fully considered, under the series comparison, the effective dynamic analysis technology of oil reservoir during super high water cut period is obtained, so provide an effective reference for the improvement of oil reservoir development work.
\end{abstract}

Keywords: super high water cut period; oil reservoir; dynamic analysis technology; research.

\section{Introduction}

The dynamic analysis of oil reservoir mainly studies the specific changes of the oil reservoir during the development process through analysis, thus finding out the relationship among the changes. In the dynamic analysis of oil reservoirs, single well-well group-unit dynamic analysis is the main analysis line, and unit dynamic analysis is the main event, therefore, strengthening the technical research on unit dynamic analysis can make the dynamic analysis technology of oil reservoirs during super high water cut period become a reality, and finally the development effect of oil fields has been improved in all aspects. In the development process of oil reservoir, under normal conditions, the water content of the oil reservoir are considered over $90 \%$, and then enters the development stage of super high water cut. Compared with the low and medium water cut development stage, the oil reservoirs during the super high water cut period are relatively low in the speed of oil recovery, and the water consumption is also relatively large, the remaining oil will be dispersed and the effect of the measures will be worse, characteristics of deterioration of well condition appear, even the overall development economic efficiency is low. How to effectively improve the development effect of these oil reservoirs, further promote the improvement of recovery ratio, finally, the economic benefit of economic development is improved, and it has a very important significance and influence for increasing production and stable production of oil fields.

\section{Purpose of Unit Dynamic Analysis}

In the later stage of entering the development of super high water cut, affected by the heterogeneity of sandstone reservoirs, and under the influence of various complex geological features, the oilfield will have a decreasing trend in recovery ratio, so in this stage, the ultimate goal of oil reservoir development management is to improve the overall ultimate recovery ratio. If the whole is facing an inefficient circle, the water and water content rise rate of the unit will decrease, at the same time, the water storage rate and water flooding index will decrease as well. The water flooding characteristic curve is also called the displacement characteristic curve; it is a curve that can fully display the relationship between oil production and water production in the water flooding development oil reservoir, to a certain extent, cumulative water production and cumulative oil production are divided according to different forms, and can also display water-oil ratio and cumulative oil production. Under normal conditions, the pressure will decrease as the saturation of the seawater increases. In the downward trend of pressure, there will be from emergency decrease to slow decrease, then emergency decrease and slow decline, and presents features that are succinct and slow alternately. 
Through the analysis and evaluation of the water flooding characteristic curve, we can carry out all-round evaluation of water injection development, reservoir recovery ratio and dynamic reserves, and specific change law and so on, at the same time, the future trend of reservoir development can be it can predicted to a certain extent. The water flooding characteristic curve is only suitable for use in some specific stages of oil injection development oilfields, in the super high water-cut period, affected by shut and stopping injection, the overall water content will decline, and eventually affects the slope of the curve.

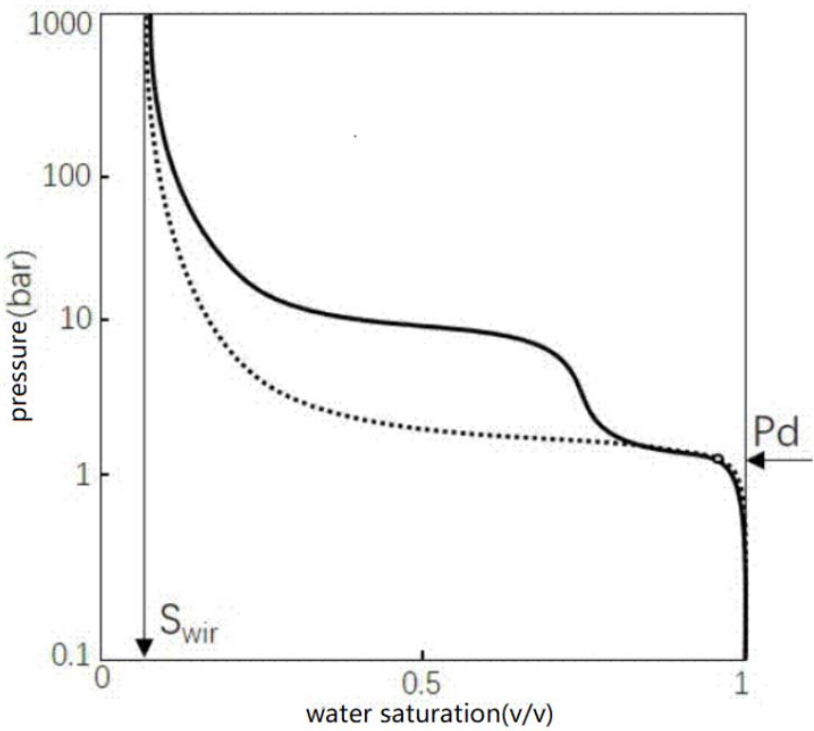

Fig.1 Water drive characteristic curve

\section{Main Content of Unit Dynamic Analysis}

\subsection{Analysis of Development Law}

The most important research objects for the analysis of development law are new wells, output, water content and liquid volume, and other development change status and regularity in some development aspects. For the index characteristics of the development dynamic of oilfield in super high water cut period, these contents are studied, it is necessary to analyze the recoverable reserves of single well control, in addition, the analysis object should involve the decline in production and the rise in water content, it is even necessary to understand the change characteristics and the specific influencing factors of liquid production. Among these indexes, the output change is the core content of the regular research; the specific nature indexes involve the change of liquid volume, the law of water change and natural changes and so on. The development of oilfields is an important link of energy construction, mastering the specific laws of oilfield development can help people to grasp the highest level of oilfield development to a certain extent, and at the same time take targeted measures to promote the efficiency and effectiveness of oilfield exploitation. Unit dynamic analysis is a key link in the dynamic analysis of oil reservoirs during super high water cut period, for the special regular analysis work, although there are certain differences under different conditions, in general, its effect is consistent, therefore, this will enable the development of oil reservoirs during super high water cut stage to reach an optimal level to a certain extent, provide effective help for China's energy construction.

\subsection{Analysis of Theoretical Comparison}

The most important thing $\mathrm{f}$ or theoretical comparative analysis is to draw a specific curve by the actual data, and compare this curve with the curve drawn by the theoretical value. On the basis of this operation link, it is also necessary to draw a curve of the average relative permeability, according to the specific relative permeability data; the other curves and the theoretical curve of recovery degree is drawn, calculates the water content and the recovery degree, even calculate some index values such 
as water storage rate, compare these contents with curves drawn from the actual data of oil reservoir, In this way, we can effectively judge whether the unit has a low efficiency cycle. When drawing the curve, it necessary to select the data, in this operation, we need to pay attention to the slope of the water flooding characteristic curve will be affected by the super high water cut period, in this process, the slope of the curve will appear slower, this situation will lead to an increase in the calculated recoverable reserves, but in reality, the reserves will not increase. Therefore, in the data selection of the curve, the data of this stage cannot be selected, and the specific of stabilized water flooding must be selected.

\section{Specific Analysis Method of Unit Dynamic Analysis Technology}

\subsection{Processing of Relative Permeability Data}

After representative phase infiltration data is carried out standardized treatment, the average relative permeability curve of the oil field can be obtained. The two-phase relative permeability of oil and water is not only affected by the storage pore structure, but also by the permeability, and some internal factors such as fluid property and wetting property will also have certain influence. Under the influence of some external factors such as different injection multiples and pressure gradients, higher water injection multiples will also reduce the saturation of residual oil, and also affect the efficiency of water flooding.

\subsection{Relationship Curve Between Water Content and Recovery Degree}

It can be found from a large amount of experimental data that the greater the viscosity of the crude oil, the greater the recovery degree in the super high water cut stage. If the theory of the relationship between water content and recovery degree and corresponding actual relationship curve are presented in the same coordinated diagram, we can clearly find out that there are valid and clear judgments about whether there is an inefficient circle in unit development.

\subsection{Increase in Water and Water Content}

Under the theoretical comparison and the analysis of the actual water content rise rate curve, the technician can judge the quality of water content. In this process, the technicians can find that there are many factors affecting water rise rate, the most common factors are the stage of containing water, the heterogeneity of the reservoir and the viscosity ratio of oil to water. These three factors are the most common factors and are three most critical factors for the overall impact. In the super high water cut stage, the slowing of the water content rise can generally be seen under the influence of these factors. The dynamic analysis technology of oil reservoirs during super high water cut stage in the implementation process, it is necessary to fully grasp the rise of water and water content, and need to fully consider the interaction between these two factors, make dynamic analysis technology more targeted and accurate, and can help people to accurately understand the reservoir conditions during the super high water cut period.

\subsection{Water Storage Rate and Water Drive Index}

Under normal conditions, the water storage rate can evaluate the effect of water injection. This index is in water injection, in addition to some ineffective water, the percentage of total water injection that can really play a role in total water injection. When the pressure of the oil reservoir is constant, the larger water storage rate is, the larger injected water and volume and volume are, at the same time, the mining effect will become more ideal. The water flooding index is the difference between the amount of intermittent water injection and the amount of water produced, this figure is compared with the ratio of the volume of oil produced in the same stage, under normal conditions, and this indicator will evaluate the effect of water injection development. If the index of the water drive is greater than zero, then the smaller the water drive index, the better the overall development effect. The super high water cut period is a very important stage in development, in this stage, the oil- 
water two-phase permeation will show some new features, under the constant understanding to the characteristics of this stage, carry out all-round research and grasp on the characteristics of dynamic indexes in super high water cut period, in the end, it will help technicians to clarify the development rules of the super high water stage.

\section{Conclusion}

In summary, during the extra high water cut period, in order to effectively improve the efficiency and recovery ratio of oil displacement, it is an effective way to increase the injection multiple, which can effectively improve the pressure gradient of water flooding. Through a large amount of experimental data and research, it can be found that the super high water cut period has the following characteristics, first, the water content rise and then fall, the output will decrease in decreasing aspects, and the ability of liquid production will drastically increase, the water-oil ratio will also increase significantly. As people's demand for energy continues to increase, new energy development and green energy technologies still need to break through, under this background, the emergence of dynamic analysis technology of oil reservoirs in super high water cut period can help technicians understand the oil reservoir condition during super high water cut period, so that better measures can be taken to improve the development efficiency of the oilfield.

\section{References}

[1]. Peng Guohong. Research on dynamic analysis technology of oil reservoirs in super high water cut period [J]. China Petroleum and Chemical Standard and Quality, 2014(03):132.

[2]. Qi Han. Dynamic analysis on determining reservoir in the period containing highly water [J]. Petrochemical Industry Technology, 2015(04):105.

[3]. Hou Yupei. Research on inefficient circulating wells and strip identification technology of oil reservoirs in super high water cut period [J].Science \& Technology and Enterprises, 2014 (9):151.

[4]. Li Haidong, Liu Daojie, Cui Jian. Research on the distribution law of remaining oil in the super high water cut period in complex small fault block reservoirs in the Gaoqiannan[J]. Petroleum Geology and Engineering, 2014 (04):74-76.

[5]. Tang Hongju. Application of detailed reservoir study in comprehensive adjustment of matured oilfield with extra-high water cut $[\mathrm{J}]$. Journal of Jianghan Petroleum University of Staff and Workers, 2014(03): 21-23.

[6]. Zhang Linfeng, Zhang Ming'an. Method for determining low efficiency circulation of water drive reservoir based on big data technology [J].Contemporary Petroleum \& Petrochemicals,2017(02):33-38. 